\title{
Effects of He radiation on cavity distribution and hardness of bulk nanolayered $\mathrm{Cu}-\mathrm{Nb}$ composites
}

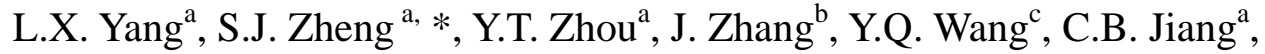 \\ N.A. Mara ${ }^{\text {c }}$ I.J. Beyerlein ${ }^{\text {d, X.L. Ma }}{ }^{\mathrm{a}}$ \\ a Shenyang National Laboratory for Materials Science, Institute of Metal Research, \\ Chinese Academy of Sciences, Shenyang 110016, China \\ ${ }^{\mathrm{b}}$ School of Energy Research, Xiamen University, Xiamen 361005, China
}

c LANL Institute for Materials Science and the Center for Integrated Nanotechnologies, Los Alamos National Laboratory, Los Alamos, NM 87545, USA

d Mechanical Engineering Department, Materials Department, University of California at Santa Barbara, Santa Barbara, CA 93106, USA

*Corresponding author. Email address: sjzheng@imr.ac.cn (S.J. Zheng)

Abstract: Interface engineering is an important strategy for developing radiation tolerant materials. In prior work, bulk nanolayered composites fabricated by accumulative roll bonding (ARB) showed outstanding radiation resistance. However, the effects of layer thickness and radiation conditions on damage distributions and their effect on hardness have not been explored. Here, we use transmission electron microscopy (TEM) and nanoindentation to investigate the effects of radiation on the distribution of radiation-induced cavities and post-radiation hardness in ARB nanolayered $\mathrm{Cu}-\mathrm{Nb}$ composites. We show that whether the cavities cross the interface depends on layer thickness and temperature, and that, remarkably, radiation could generate softening, not always hardening. We posit that the softening mainly results from the recovery of dislocations stored in the crystal after the bulk forming ARB processing due to $\mathrm{He}$ radiation and this phenomenon offsets radiation-induced hardening as layers become finer and temperatures rise.

Keywords: interface, cavity, softening, radiation, nanolayered composite 


\section{Introduction}

Structural materials in nuclear reactors suffer damage due to long-term exposure to high temperatures, high stress, corrosion, and radiation. Voids and bubbles, which are some of the major forms of irradiation-induced damage, are generated by the $\mathrm{He}$ radiation that accompanies endothermic $(n, \alpha)$ reactions. These He bubbles and voids lead to detrimental changes in the material microstructure, dimensions, and structural performance, such as swelling, hardening, and embrittlement [1-6]. Hardening, for example, can be severe. In 316LN stainless steel, He radiation that leaves peak $\mathrm{He}$ concentrations of $10 \%$ in the material has been reported to cause enhancements in hardening $\Delta \mathrm{H}$ up to $90 \%$ percent [7].

The enhancement in hardness, $\Delta \mathrm{H}$, is thought to result from the bubbles or voids, or hereinafter generically called cavities, remaining after irradiation and their ability to hinder dislocation motion. Accordingly, $\Delta \mathrm{H}$ would increase with the size and/or density of cavities in the crystal as they would present larger and/or more frequent obstacles to dislocation glide. This relationship between cavity properties and $\Delta H$ has been described by the Friedel-Kroupa-Hirsch $(\mathrm{FKH})$ relation $[8,9], \Delta \mathrm{H} \approx$ $3 \Delta \sigma_{\text {cavity }}=\frac{1}{8} M G b d N_{\text {cavity }}^{2 / 3}(1)$, where $\mathrm{M}$ is Taylor factor reflecting crystal orientation; $\mathrm{G}$ is the shear modulus (GPa); $b$ is the Burgers vector $(\mathrm{nm})$ of the dislocation; $d$ is the cavity diameter $(\mathrm{nm})$ and $\mathrm{N}$ is the cavity density $\left(\mathrm{m}^{-3}\right)$. Thus, for a given material, the larger the cavity size and/or cavity density in the crystal, the higher $\Delta \mathrm{H}$ is.

Extensive studies have demonstrated that interfaces and grain boundaries can serve as excellent sinks for point defects [10, 11], and can store He ions efficiently [12], therefore reducing cavity sizes and densities in the adjoining crystals and minimizing post-irradiation swelling and hardening [13-16]. Using deposited $\mathrm{Cu}-\mathrm{Nb}$ multilayer thin films as an interface-dominant model material system, Li et al. [16] demonstrated that when the layer thickness (or interface spacing) reduced from $70 \mathrm{~nm}$ to $5 \mathrm{~nm}$, the He cavity volume fraction within the layers decreased with concomitant reductions in 
hardening enhancement $\Delta \mathrm{H}$. This study is just one of the many examples suggesting that introduction of biphase interfaces can be an important strategy to design radiation-resistant materials.

Most of these studies on the promising mitigation effects of biphase interfaces were carried out in thin films fabricated by bottom-up techniques, such as physical vapor deposition [15]. Recently, simultaneous high strength and outstanding thermal stability were demonstrated in bulk nanolayered $\mathrm{Cu}-\mathrm{Nb}$ composites fabricated by a top-down processing method, called accumulative roll bonding (ARB $\mathrm{Cu}-\mathrm{Nb})[15,17$, 18]. Unlike bottom-up deposition techniques, the ARB process can be scaled up to manufacture sheet metal in quantities suitable for structural components. Microscopic analyses revealed that just like the prior $\mathrm{Cu}-\mathrm{Nb}$ nanocomposite studies, no voids formed in the interfaces and only within the crystalline layers, suggesting that void formation was hindered in the interfaces [19]. Moreover, the voids that formed in the crystal near the interfaces tended to stay on the $\mathrm{Cu}$ side of the interface and predominately where non-parallel misfit dislocations in the interface intersected [20]. The preference of the $\mathrm{Cu}$ phase arises because $\mathrm{Cu}$ has a smaller surface energy than $\mathrm{Nb}$ and wets the regions of highest interface energy, which is where the misfit dislocations in the $\mathrm{Cu}-\mathrm{Nb}$ interface intersect $[20,21]$. Thus, like the thin films, the bulk sheet material exhibits similar behavior, but with it, we have much more versatility in processing and potential for achieving target interface properties [18]. Furthermore, the correlation between void spacing along the boundaries and interface dislocation structure suggests that the distribution of He bubbles or voids could be tuned by engineering the interface.

It should be mentioned that in these previous studies, He was directly implanted into transmission electron microscope (TEM) samples [19, 20]. TEM samples are thin films, in which the thicknesses of observable regions are usually less than $100 \mathrm{~nm}$. For such fine thicknesses, He ions transmit across the samples and generating damage in their wake. The type of damage, however, should be different from that generated 
when the He ions terminate within the bulk material.

Also, as mentioned, temperature, fluence, and grain size (layer thickness) are dominant factors influencing cavity size and distribution $[1,4,5,22]$, and hence $\Delta \mathrm{H}$. Such effects have not been investigated in these bulk structural $\mathrm{Cu}-\mathrm{Nb}$ composites. Here, in order to evaluate the radiation resistance of bulk $\mathrm{Cu}-\mathrm{Nb}$ composites, we investigate interface effects on cavity distribution and $\Delta \mathrm{H}$. As the damage could include either bubbles or voids, hereinafter we use the term cavity to generically encompass both types of damage. Our analyses find that whether the cavities cross the interface depends on layer thickness and temperature, and that, remarkably, radiation could generate softening, not hardening. We rationalize that softening results from annihilation of the dislocations stored within the crystal after the bulk forming ARB processing by interactions with radiation-induced defects, as well as from thermal annealing. For finer layers, such as $<20 \mathrm{~nm}$, there is less room for dislocations to move and dislocation annihilation at cavities dominates over dislocation blockage by cavities. These effects, such as cavity formation in interfaces and softening, were not reported before for nanolayered composites, since other temperatures and fluence conditions were not considered.

\section{Materials and methods}

The ARB $\mathrm{Cu}-\mathrm{Nb}$ composites used for this work started with polycrystalline sheets of reactor grade $\mathrm{Nb}$ (99.97\% pure, ATI-Wah Chang) and oxide-free high conductivity $\mathrm{Cu}$ (99.99\% pure, Southern Copper and Supply) in a 50-50\% volume ratio. Details on the ARB process, which included repeatedly cleaning, stacking, roll-bonding, and cutting, can be found in [17]. ARB $\mathrm{Cu}-\mathrm{Nb}$ composites chosen for this radiation study are 300 $\mu \mathrm{m}$ thick sheets with nominal layer thicknesses of 16 and $58 \mathrm{~nm}$ respectively. These materials have similar grain structures, with one grain spanning the layer thickness, and textures [23]. He-ion irradiation was conducted using a Danfysik $200 \mathrm{kV}$ ion implanter at Los Alamos National Laboratory at room temperature (RT) and $450^{\circ} \mathrm{C}$. All the samples were mounted on a stage with cooling and heating systems which can 
monitor the temperature precisely. To reach a fluence of $2 \times 10^{17}$ ions $/ \mathrm{cm}^{2}$, the radiation process lasted for about 5 hours. The SRIM calculation for the radiation of the $58 \mathrm{~nm}$ sample shown in Fig.1a indicates that the most intense damage and $\mathrm{He}$ concentration are about $16 \mathrm{dpa}$ and 11 at.\% at depths of about 500 and $550 \mathrm{~nm}$ respectively. The SRIM calculations for the $16 \mathrm{~nm}$ samples showed a similar damage and He-concentration profile vs. depth as those of the $58 \mathrm{~nm}$ samples and hence are not shown here for compactness. For comparison, radiation with fluences of $2 \times 10^{17}$ ions $/ \mathrm{cm}^{2}$ and $6.5 \times 10^{17}$ ions $/ \mathrm{cm}^{2}$ at RT were performed on the $58 \mathrm{~nm} \mathrm{ARB} \mathrm{Cu-Nb}$ composites, which required about 10 hours. More detailed information for the sample can be found in table 1 .

To investigate the distribution of voids and bubbles after irradiation, TEM samples were prepared by a conventional cross-sectioning method, consisting of low-speed saw cutting, mechanical polishing, dimpling, and ion milling on a Gatan precision ion polishing system (PIPS) operated at $3.5 \mathrm{kV}$. TEM was performed on a Tecnai F30 (FEI) operated at $300 \mathrm{kV}$.

To test for hardening enhancements, the hardness before and after radiation was measured using nano-indentation on a Nanoindenter G200 (Agilent). Indents were performed to a depth of $500 \mathrm{~nm}$ with a target strain rate of $0.05 \mathrm{~s}^{-1}$. Hardness measurements were made in the continuous stiffness measurement mode. Average hardness values were calculated from 16 separate indents with a depth range of $460-480 \mathrm{~nm}$.

Under the He radiation conditions applied here, He concentrations can be detected up

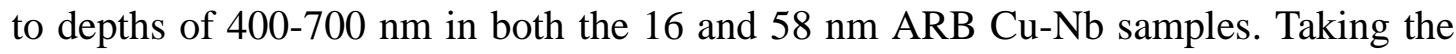
58-RT sample as an example, as shown in Fig. 1b, the maximum He concentration appears at a depth of $550 \mathrm{~nm}$, which is consistent with the SRIM calculations. This $\mathrm{He}$ distribution also agrees well with a previous study using the same He radiation conditions [24]. Hereinafter, we focus on the structural evolution at depths where $\mathrm{He}$ 
ions have presumably concentrated.

\section{Results}

Figure 2 shows TEM images of the cavity distribution in the $16 \mathrm{~nm} \mathrm{ARB} \mathrm{Cu}-\mathrm{Nb}$ sample radiated at both $\mathrm{RT}$ and $450^{\circ} \mathrm{C}$. In this fine-layered composite, He cavities are found within the layers and along the $\mathrm{Cu}-\mathrm{Nb}$ interface but not across or within them. We refer to this cavity configuration as a confined-layered distribution. After RT irradiation (Fig. 2a), He cavities appear as the bright spots approximately $1 \mathrm{~nm}$ in diameter in both the $\mathrm{Nb}$ and $\mathrm{Cu}$ layers. The cavity density is larger and the cavities are bigger along the $\mathrm{Cu}-\mathrm{Nb}$ interfaces than within the layer interior, suggesting that the interfaces can act as effective traps for He ions. Moreover, these interface-touching cavities are found in the $\mathrm{Cu}$ layers than in the $\mathrm{Nb}$ layers, which is consistent with prior observations on another material system, $\mathrm{Cu}-\mathrm{Ag}$, as well as the more general theoretical prediction based on interface wetting of He cavities [12, 20].

Figure $2 \mathrm{~b}$ shows that the same confined-layered distribution develops in the $16 \mathrm{~nm}$ ARB $\mathrm{Cu}-\mathrm{Nb}$ sample radiated at the higher temperature $450{ }^{\circ} \mathrm{C}$. After radiation at $450^{\circ} \mathrm{C}$, the cavities in the $\mathrm{Nb}$ and $\mathrm{Cu}$ are larger than at $\mathrm{RT}$, being about $1-2 \mathrm{~nm}$ in $\mathrm{Nb}$ and significantly larger, approximately $10 \mathrm{~nm}$ in the $\mathrm{Cu}$. Again, as in the RT sample, the cavities do not form within the layers. Some cavities even span the $\mathrm{Cu}$ layer as indicated by an arrow in Fig. $3 \mathrm{~b}$ or wet the interfaces, as shown in the bottom $\mathrm{Cu}$ layer in Fig. 3b, but nonetheless, remain confined within the $\mathrm{Cu}$ layers. This observation is consistent with a previous study of the confinement effect of the interface on $\mathrm{He}$ cavities in $\mathrm{Cu}-\mathrm{Nb}$ multilayers fabricated via physical vapor deposition (PVD) with layer thickness of 5 and $120 \mathrm{~nm}$ [25].

In the foregoing cases, the interface spacing was very fine and the cavities did not form in the interfaces. First, to investigate the effects of interface spacing on cavity density, we repeated the study with $58 \mathrm{~nm}$ ARB $\mathrm{Cu}-\mathrm{Nb}$ composites after He radiation 
at both RT and $450^{\circ} \mathrm{C}$. Figure $3 \mathrm{a}$ shows the TEM image displaying the typical distribution of cavities seen in the $58 \mathrm{~nm}-\mathrm{RT}$ sample. As shown in Fig. 3a, the cavities exhibit a similar confined-layered distribution as the RT $16 \mathrm{~nm}$ samples. The average cavity size is about $1 \mathrm{~nm}$ and the cavities are found in both the $\mathrm{Cu}$ and $\mathrm{Nb}$ layers. The cavities in the $16 \mathrm{~nm}$ composites bear the same properties, indicating that the layer thickness, i.e. interface density, apparently does not affect the distribution of cavities and their size at RT.

Second, to explore the dependence of this interface effect on fluence, we studied the distribution of cavities in the $58 \mathrm{~nm}$-RT samples that were irradiated at a higher fluence of $6.5 \times 10^{17}$ ions/cm. From the image shown in Fig. 3b, it is clear that, as the fluence increases from $2 \times 10^{17}$ to $6.5 \times 10^{17}$ ions $/ \mathrm{cm}$, the cavity size along the $\mathrm{Cu}-\mathrm{Nb}$ interfaces increases to about $6 \mathrm{~nm}$, a trend that generally is not surprising. Thus, based on the FKH relation, we can expect that these crystalline cavities would lead to an increase in hardening compared to the unirradiated sample. Yet, we note that the cavities in both the $\mathrm{Cu}$ and $\mathrm{Nb}$ layers still have a confined-layered distribution. Thus, even increasing the fluence does not cause cavities to form within the interfaces but causes them to only grow bigger at RT.

Last, we examine the effects of temperature on the distribution of cavities. It is found that unlike the $16 \mathrm{~nm}$ ARB material, in the $58 \mathrm{~nm} \mathrm{ARB} \mathrm{Cu-Nb}$ composites radiated at high temperature, the cavities cross or form within the $\mathrm{Cu}-\mathrm{Nb}$ interfaces. This defect configuration, in which cavities cross the interface, will be referred to as a cross-layered distribution. As shown in Fig. 3c of the 58-450 sample, the cavity size, which is about $3 \mathrm{~nm}$ in the Nb layers, is much bigger than that in the $58 \mathrm{~nm}$-RT and the $58 \mathrm{~nm}-\mathrm{RT}-6.5$ samples. Most interestingly, the cavities cross the $\mathrm{Cu}-\mathrm{Nb}$ interfaces, and possess a much larger average size of $16 \mathrm{~nm}$, while there are almost no cavities in the $\mathrm{Cu}$ layers. This result suggests that a cross-layered distribution can form provided that the temperatures are high and layers are thick enough. 
In all irradiated samples, cavities formed in either or both the $\mathrm{Cu}$ and $\mathrm{Nb}$ layers. It can, therefore, be expected that radiation hardening would occur. As mentioned, enhancements in hardening after He irradiation are common in metals and have been reported in PVD $\mathrm{Cu}-\mathrm{Nb}$ nanolaminates in prior work $[6,7]$. Next, we examine the hardness of these $16 \mathrm{~nm}$ and $58 \mathrm{~nm}$ nanolaminates before and after irradiation. Fig. 4 shows the results of hardness tests on the He-irradiated $16 \mathrm{~nm}$ and $58 \mathrm{~nm}$ ARB Cu-Nb composites. Beginning with the finer-layered $16 \mathrm{~nm}$ composite, we observe that remarkably these samples exhibit softening rather than hardening after He-irradiation at both RT and $450^{\circ} \mathrm{C}$. The unirradiated 16-nm sample has the highest hardness of $4.95 \pm 0.29 \mathrm{GPa}$ among all samples. After RT and $450^{\circ} \mathrm{C}$ He irradiation, it softened to $4.73 \pm 0.19 \mathrm{GPa}$ and $4.56 \pm 0.74 \mathrm{GPa}$, respectively. Like the other fine-layered $\mathrm{Cu}-\mathrm{Nb}$ composites made by PVD, these composites formed cavities in the layers and not interfaces, as seen in Fig. 2. The cavity size even increased with an increase in radiation temperature from $\mathrm{RT}$ to $450^{\circ} \mathrm{C}$, but yet the material also softened at the higher temperature.

In the $58 \mathrm{~nm}$ samples, we find that the commonly observed hardening takes place after room temperature He radiation. The hardness of the unirradiated $58 \mathrm{~nm}$ sample, which is $3.75 \pm 0.26 \mathrm{GPa}$, increases to $3.94 \pm 0.26 \mathrm{GPa}$ and $4.43 \pm 0.25 \mathrm{GPa}$ in the 58 -RT and 58-RT-6.5 samples, respectively. The enhancement $\Delta \mathrm{H}$ is higher for the sample exposed to the higher fluence, which would be anticipated since the higher fluences were found to lead to larger cavities (Fig. 3). Thus, unlike the $16 \mathrm{~nm}$ samples, the $58 \mathrm{~nm}$ samples, which also exhibited a confined-layered cavity distribution, followed conventional expectation. Moreover, the interfaces and textures in the $58 \mathrm{~nm}$ and $16 \mathrm{~nm}$ are very similar [17]. Therefore the unusual softening seen in the $16 \mathrm{~nm}$ sample could be a layer thickness effect.

Finally, we note the interesting observation that the irradiated $58 \mathrm{~nm}-450^{\circ} \mathrm{C}$ sample also shows softening relative to the $58 \mathrm{~nm}$-AR sample. Thus it responds to radiation in a similar manner as the $16 \mathrm{~nm}-\mathrm{RT}$ and $16 \mathrm{~nm}-450^{\circ} \mathrm{C}$ samples. In this case, 
however, the cavity distribution was distinct from the others, lying within the interfaces and $\mathrm{Nb}$ layer but not the $\mathrm{Cu}$ layer. To summarize, we see an unusual post-irradiation softening in the $16 \mathrm{~nm}$ samples radiated at $\mathrm{RT}$ and $450^{\circ} \mathrm{C}$, which had a confined-layer distribution and the $58 \mathrm{~nm}$ sample radiated at $450^{\circ} \mathrm{C}$, which had a cross-layer distribution.

\section{Discussion}

The well-known phenomenon of He cavity induced hardening took place in the 58 $\mathrm{nm}-\mathrm{RT}$ and $58 \mathrm{~nm}-\mathrm{RT}-6.5$ samples. According to the FKH relationship, $\Delta \mathrm{H}$ would increase linearly with $d N_{\text {cavity }}^{2 / 3}$. Although the increment of cavity density is difficult to determine, the cavities size increases, as shown in Figs. 3a and 3b, as the fluence increases. As the fluence increases from $2 \times 10^{17}$ to $6.5 \times 10^{17} \mathrm{ions} / \mathrm{cm}^{2}$, the increment of hardness also increases from $5.0 \%$ to $18 \%$. Thus, both the fluence and increment of hardness increase about three times, and the linear FKH relation between the fluence and increment of hardness evidently applies in this case.

Post-irradiation softening is an interesting finding in the present work and is not captured by the FKH relation. It presumes that cavities lead to hardening and for the same material composition and texture, only reductions in $\mathrm{d}$ and/or $\mathrm{N}$ can lead to reductions in hardening. For all layer thickness, nano-sized cavities form as a result of the irradiation, but in most of the cases we tested, softening, not hardening, was found. Specifically softening occurs in both the $16 \mathrm{~nm}$ and $58 \mathrm{~nm}$ samples irradiated at $450^{\circ} \mathrm{C}$ and thus it can happen whether the nano-cavities lie along the interfaces, as in the 16 $\mathrm{nm}$ (confined-layer distribution), or across the interfaces, as in the $58 \mathrm{~nm}-450^{\circ} \mathrm{C}$ (cross-layer distribution).

One reason for the softening should be thermal annealing. High temperatures could diminish radiation hardening. It has been reported that the density of bubbles decreases rapidly with increasing temperature [5]. For example, the bubble density 
was observed to decrease about two orders of magnitude as the temperature increases from RT to a temperature near $0.5 \mathrm{~T}_{\mathrm{m}}$ [5]. In the present work, $450^{\circ} \mathrm{C}$ is close to 0.5 $\mathrm{T}_{\mathrm{m}}$ of $\mathrm{Cu}$, so it is reasonable that cavity density in the $\mathrm{Cu}$ phase of these samples would decrease about two orders of magnitude as well. Also, when the temperature increases from RT to $450^{\circ} \mathrm{C}$, cavity size only increases about one to one and half orders of magnitude as indicated in Figs. 2-3. Although $\mathrm{Nb}$ has a $\mathrm{T}_{\mathrm{m}}$ of $2477^{\circ} \mathrm{C}$ and thus the temperature of $450^{\circ} \mathrm{C}$ does not show as strong an effect on hardness as that for $\mathrm{Cu}, \mathrm{Nb}$ should still display the same trend of hardness change with $\mathrm{Cu}$. So according to the FKH relation, the radiation hardening could be reduced for samples radiated at $450^{\circ} \mathrm{C}$.

Other unusual effects of nano-sized radiation-induced cavities have been reported. Recently, it has been found that nanosized He cavities could improve ductility of a metallic glass with no sacrifice in yield and ultimate tensile strength [26]. Also, Ding et. al [27] has shown a similar ductility enhancement by nanosized He cavities in single crystal $\mathrm{Cu}$, and they rationalized this phenomenon results from $\mathrm{He}$ cavities acting as both dislocation sources and shearable obstacles, which promote dislocation storage and reduce dislocation mean free path. However, no softening after irradiation has been reported by far.

The cavities introduce a second type of interface, at which dislocations can be annihilated or nucleated or their glide motion hindered when the material is deformed. In coarser materials, dislocations have other sources and sinks for dislocations like biphase interfaces, surfaces, grain boundaries and stored dislocations (substructure, tangles). Usually, nano-sized cavities predominately act as obstacles to dislocation glide, rather than as sources or sinks, enhancing the hardness, as is reflected in the FKH relation. In nanomaterials, however, we speculate that in the cases of post-radiation softening, cavities could play a role as a newly introduced sink for dislocations. Both the ARB $\mathrm{Cu}-\mathrm{Nb} 16 \mathrm{~nm}$ and $58 \mathrm{~nm}$ nanolayered composites used in the present study were rolled at room temperature without any annealing process, and 
consequently contained a high density of dislocations as shown in Fig. 5. After He radiation, as shown in Figs. 2 and 3, we find that the dislocation density has decreased dramatically. Similar observations of annihilation of dislocations as a result of interactions between dislocations and point defects induced by radiation have been reported in pure $\mathrm{Cu}$ [28] and a Ni-based alloy [29]. Thus, the reduction in hardness could reflect the drop in stored dislocation density. By virtue of the fabrication method, the $\mathrm{Cu}-\mathrm{Nb}$ samples made by PVD had little to no stored dislocation density in the layers. Thus, softening was not seen there. Moreover, when cavity size is big enough to be comparable to the layer thickness, as the cases in both the $16 \mathrm{~nm}$ and 58 $\mathrm{nm}$ samples irradiated at $450^{\circ} \mathrm{C}$, the cavities may enhance dislocation behavior during plastic deformation. First, although small cavity could harden metallic materials, large cavities are rather weak barriers to dislocations, and even are sources of dislocations owing to their large surface. Second, the high hardness of $\mathrm{Cu} / \mathrm{Nb}$ composites arises from their semi-coherent interfaces. The disruption of layer interfaces by significantly large cavities could reduce the interface barrier strength to the transmission of dislocations.

We find here that whether or not the softening effect of irradiation dominates apparently depends on layer thickness and temperature. In the $16 \mathrm{~nm}$, dislocation motion is confined by the interface but not the small cavities, and cavities play a role in annihilation of dislocation during radiation, moreover large cavities may contribute to dislocation dominated plastic deformation. Consequently for these finer layers, softening manifests. In the thicker layers of $58 \mathrm{~nm}$, however, dislocation motion is less confined [30] and the obstacle, annihilation, and source effects of cavities compete. At room temperature, the obstacle effect dominates and the conventional post-radiation hardening occurs, but, at higher temperatures, the annihilation and source effects could dominates and the unusual post-radiation softening ensues.

\section{Conclusions}

In summary, using TEM and and nanoindentation, we studied the effects of radiation 
on the damage state and hardness of bulk $\mathrm{Cu}-\mathrm{Nb}$ nanolayered composites fabricated by accumulative roll bonding (ARB). The results show that the cavity distribution after radiation, that is whether they form in the layers and/or within the interfaces, is found to depend on nanolayer thickness and radiation temperature. A significant result of this work is the observation of radiation induced softening, in which the hardness decreases rather than the anticipated increases as seen frequently in other metals. The unusual softening is rationalized primarily to annihilation of dislocations stored in the crystal after the bulk forming ARB processing owing to the radiation-induced cavities and thermal annealing. Finer layers and higher temperatures promote recovery of these dislocations over blockage of dislocation motion at the cavities.

\section{Acknowledgements}

S. Z. gratefully acknowledges support for this research by "Hundred Talents Project" of Chinese Academy of Sciences, "Thousand Youth Talents Plan" of China, National Natural Science Foundation of China (grant number 51401208), and Shenyang National Laboratory for Materials Science (grant number 2015RP18). This work was performed, in part, at the Center for Integrated Nanotechnologies, an Office of Science User Facility operated for the U.S. Department of Energy (DOE) Office of Science. Los Alamos National Laboratory, an affirmative action equal opportunity employer, is operated by Los Alamos National Security, LLC, for the National Nuclear Security Administration of the U.S. Department of Energy under contract DE-AC52-06NA25396.

\section{Reference}

1. K. Farrell, EXPERIMENTAL EFFECTS OF HELIUM ON CAVITY FORMATION DURING IRRADIATION - A REVIEW, Radiation Effects and Defects in Solids. 53 (1980) 175-194.

2. S.J. Zinkle, W.G. Wolfer, G.L. Kulcinski, and L.E. Seitzman, STABILITY OF VACANCY CLUSTERS IN METALS .2. EFFECT OF OXYGEN AND HELIUM ON VOID FORMATION IN METALS, Philosophical Magazine a-Physics of Condensed Matter Structure Defects and Mechanical Properties. 55 (1987) 127-140.

3. G.E. LUCAS, THE EVOLUTION OF MECHANICAL PROPERTY CHANGE IN IRRADIATED AUSTENITIC STAINLESS-STEELS, Journal of Nuclear Materials. 206 (1993) 287-305. 
4. H. Trinkaus and B.N. Singh, Helium accumulation in metals during irradiation - where do we stand?, Journal of Nuclear Materials. 323 (2003) 229-242.

5. S.J. Zinkle, 1.03 - Radiation-Induced Effects on Microstructure, in Comprehensive Nuclear Materials, R.J.M. Konings, Editor. 2012, Elsevier: Oxford. p. 65-98.

6. M.J. Makin and F.J. Minter, IRRADIATION HARDENING IN COPPER AND NICKEL, Acta Metallurgica. 8 (1960) 691-699.

7. J.D. Hunn, E.H. Lee, T.S. Byun, and L.K. Mansur, Helium and hydrogen induced hardening in 316LN stainless steel, Journal of Nuclear Materials. 282 (2000) 131-136.

8. J. Friedel, CXXX. On the linear work hardening mate of face-centred cubic single crystals, The London, Edinburgh, and Dublin Philosophical Magazine and Journal of Science. 46 (1955) 1169-1186.

9. F. Kroupa and P.B. Hirsch, Elastic interaction between prismatic dislocation loops and straight dislocations, Discussions of the Faraday Society. 38 (1964) 49-55.

10. M.J. Demkowicz, R.G. Hoagland, and J.P. Hirth, Interface structure and radiation damage resistance in Cu-Nb multilayer nanocomposites, Phys. Rev. Lett. 100 (2008) 136102.

11. X.Y. Liu, B.P. Uberuaga, M.J. Demkowicz, T.C. Germann, A. Misra, and M. Nastasi, Mechanism for recombination of radiation-induced point defects at interphase boundaries, Physical Review B. 85 (2012).

12. A. Kashinath, A. Misra, and M.J. Demkowicz, Stable Storage of Helium in Nanoscale Platelets at Semicoherent Interfaces, Phys. Rev. Lett. 110 (2013) 086101.

13. A. Misra, M.J. Demkowicz, X. Zhang, and R.G. Hoagland, The radiation damage tolerance of ultra-high strength nanolayered composites, Jom. 59 (2007) 62-65.

14. X. Zhang, E.G. Fu, A. Misra, and M.J. Demkowicz, Interface-enabled Defect Reduction in He Ion Irradiated Metallic Multilayers, Jom. 62 (2010) 75-78.

15. I.J. Beyerlein, A. Caro, M.J. Demkowicz, N.A. Mara, A. Misra, and B.P. Uberuaga, Radiation damage tolerant nanomaterials, Materials Today. 16 (2013) 443-449.

16. N. Li, M. Nastasi, and A. Misra, Defect structures and hardening mechanisms in high dose helium ion implanted $\mathrm{Cu}$ and $\mathrm{Cu} / \mathrm{Nb}$ multilayer thin films, Int. J. Plast. 32-33 (2012) 1-16.

17. S. Zheng, I.J. Beyerlein, J.S. Carpenter, K. Kang, J. Wang, W. Han, and N.A. Mara, High-strength and thermally stable bulk nanolayered composites due to twin-induced interfaces, Nature Communications. 4 (2013).

18. S.J. Zheng, J.S. Carpenter, R.J. McCabe, I.J. Beyehein, and N.A. Mara, Engineering Interface Structures and Thermal Stabilities via SPD Processing in Bulk Nanostructured Metals, Scientific Reports. 4 (2014) 4226.

19. W.Z. Han, M.J. Demkowicz, N.A. Mara, E.G. Fu, S. Sinha, A.D. Rollett, Y.Q. Wang, J.S. Carpenter, I.J. Beyerlein, and A. Misra, Design of Radiation Tolerant Materials Via Interface Engineering, Adv. Mater. 25 (2013) 6975-6979.

20. S. Zheng, S. Shao, J. Zhang, Y. Wang, M.J. Demkowicz, I.J. Beyerlein, and N.A. Mara, Adhesion of voids to bimetal interfaces with non-uniform energies, Scientific Reports. 5 (2015) 15428.

21. S.J. Zheng, I.J. Beyerlein, J. Wang, J.S. Carpenter, W.Z. Han, and N.A. Mara, Deformation twinning mechanisms from bimetal interfaces as revealed by in situ straining in the TEM, Acta Materialia. 60 (2012) 5858-5866.

22. G.M. Cheng, W.Z. Xu, Y.Q. Wang, A. Misra, and Y.T. Zhu, Grain size effect on radiation tolerance of nanocrystalline Mo, Scripta Materialia. 123 (2016) 90-94. 
23. I.J. Beyerlein, J.R. Mayeur, R.J. McCabe, S.J. Zheng, J.S. Carpenter, and N.A. Mara, Influence of slip and twinning on the crystallographic stability of bimetal interfaces in nanocomposites under deformation, Acta Materialia. 72 (2014) 137-147.

24. W.Z. Han, N.A. Mara, Y.Q. Wang, A. Misra, and M.J. Demkowicz, He implantation of bulk $\mathrm{Cu}-\mathrm{Nb}$ nanocomposites fabricated by accumulated roll bonding, Journal of Nuclear Materials. 452 (2014) 57-60.

25. K. Hattar, M.J. Demkowicz, A. Misra, I.M. Robertson, and R.G. Hoagland, Arrest of He bubble growth in Cu-Nb multilayer nanocomposites, Scripta Materialia. 58 (2008) 541-544.

26. R. Liontas, X.W. Gu, E.G. Fu, Y.Q. Wang, N. Li, N. Mara, and J.R. Greer, Effects of Helium Implantation on the Tensile Properties and Microstructure of Ni73P27 Metallic Glass Nanostructures, Nano Letters. 14 (2014) 5176-5183.

27. M.-S. Ding, J.-P. Du, L. Wan, S. Ogata, L. Tian, E. Ma, W.-Z. Han, J. Li, and Z.-W. Shan, Radiation-Induced Helium Nanobubbles Enhance Ductility in Submicron-Sized Single-Crystalline Copper, Nano Letters. 16 (2016) 4118-4124.

28. C.J. Meechan, ANNEALING OF COLD-WORKED COPPER BY ELECTRON IRRADIATION, Journal of Applied Physics. 28 (1957) 197-200.

29. H.C. Chen, D.H. Li, R.D. Lui, H.F. Huang, J.J. Li, G.H. Lei, Q. Huang, L.M. Bao, L. Yan, X.T. Zhou, and Z.Y. Zhu, Ion irradiation induced disappearance of dislocations in a nickel-based alloy, Nuclear Instruments \& Methods in Physics Research Section B-Beam Interactions with Materials and Atoms. 377 (2016) 94-98.

30. A. Misra, J.P. Hirth, and R.G. Hoagland, Length-scale-dependent deformation mechanisms in incoherent metallic multilayered composites, Acta Materialia. 53 (2005) 4817-4824.

\section{Captions:}

Figure 1(a) SRIM calculation of damage and He concentration via depth, (b) cross-section TEM image of the 58-RT sample, in which the local enlarged region marked with a white square shows the concentrated He bubbles. The SRIM calculations and TEM results of damage and He concentration via depth for the other samples are similar.

Figure 2 Microstructures of $16 \mathrm{~nm}$ ARB $\mathrm{Cu}-\mathrm{Nb}$ composites after He radiation: (a) 16-RT, (b) 16-450.

Figure 3 Microstructures of $58 \mathrm{~nm}$ ARB $\mathrm{Cu}-\mathrm{Nb}$ composites after He radiation: (a) 58-RT, (b) 58-RT-6.5, (c) 58-450.

Figure 4 Hardness evolution of the $16 \mathrm{~nm}$ and $58 \mathrm{~nm}$ ARB Cu-Nb composites.

Figure 5 Microstructures of the ARB $\mathrm{Cu}-\mathrm{Nb}$ composites before He radiation showing dense dislocations: (a) 16-AR, (b) 58-AR. 
Table 1 sample information

\begin{tabular}{|l|l|l|l|}
\hline Sample name & $\begin{array}{l}\text { Layer } \\
\text { thickness } \\
(\mathrm{nm})\end{array}$ & $\begin{array}{l}\text { Radiation } \\
\text { fluence } \\
\text { (ions/cm }\end{array}$ & Radiation temperature \\
\hline $16 \mathrm{~nm}-\mathrm{AR}$ (as rolled) & 16 & none & none \\
\hline $16 \mathrm{~nm}-\mathrm{RT}$ & 16 & $2 \times 10^{17}$ & Room temperature (RT) \\
\hline $16 \mathrm{~nm}-450^{\circ} \mathrm{C}$ & 16 & $2 \times 10^{17}$ & $450^{\circ} \mathrm{C}$ \\
\hline $58 \mathrm{~nm}-\mathrm{AR}($ as rolled) & 58 & none & none \\
\hline $58 \mathrm{~nm}-\mathrm{RT}$ & 58 & $2 \times 10^{17}$ & Room temperature (RT) \\
\hline $58 \mathrm{~nm}-\mathrm{RT}-6.5$ & 58 & $6.5 \times 10^{17}$ & Room temperature (RT) \\
\hline $58 \mathrm{~nm}-450^{\circ} \mathrm{C}$ & 58 & $2 \times 10^{17}$ & $450^{\circ} \mathrm{C}$ \\
\hline
\end{tabular}









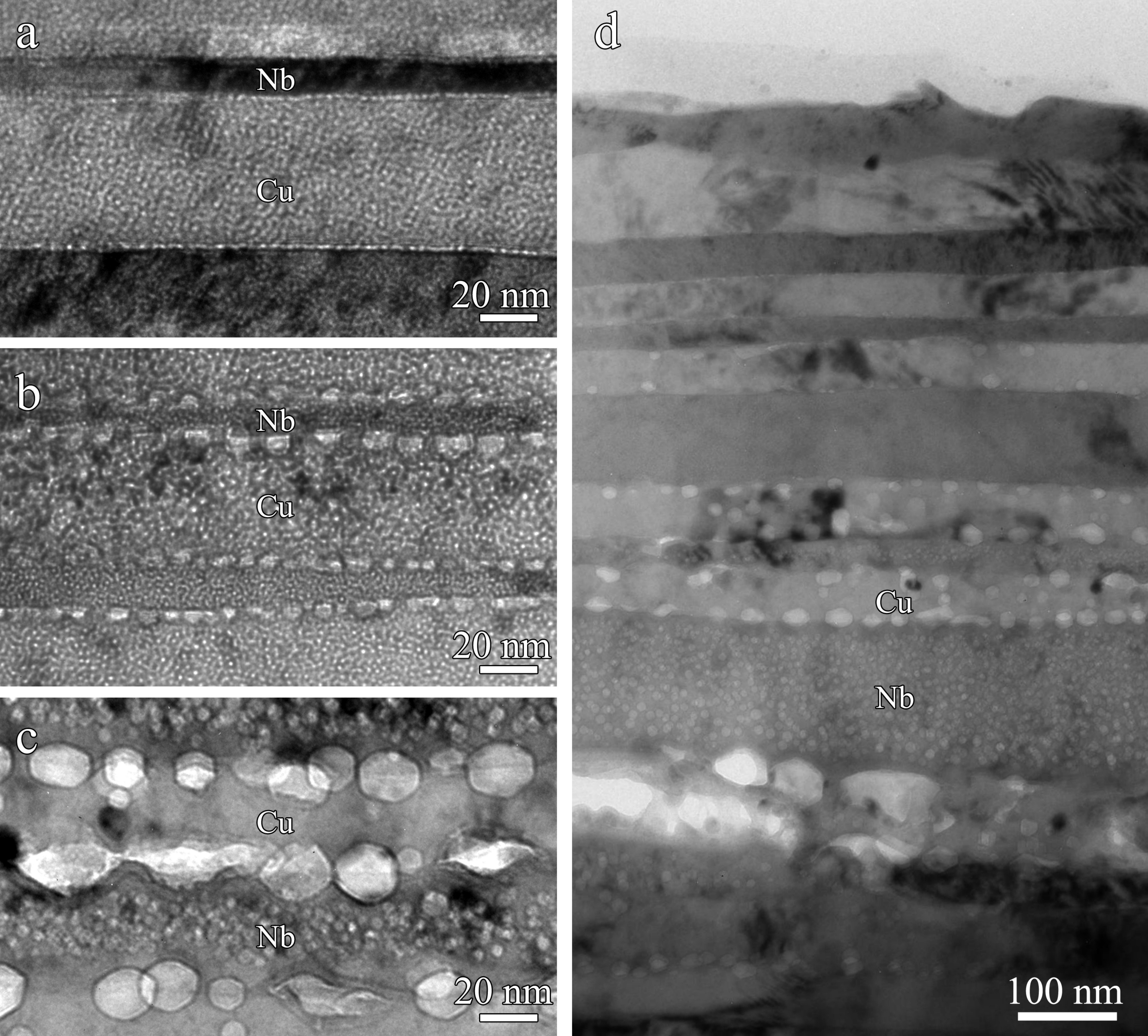




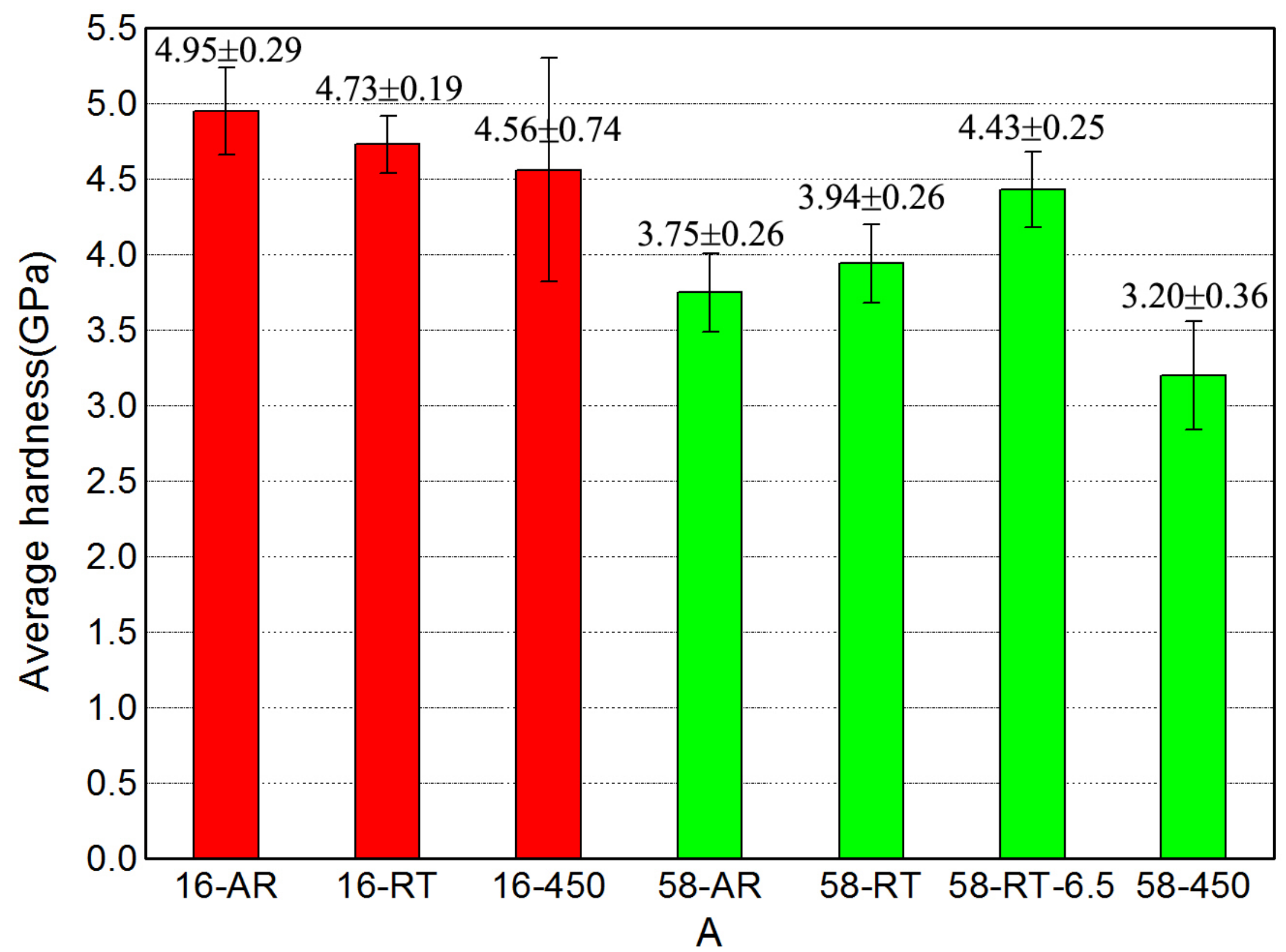




\section{a}

Menasive

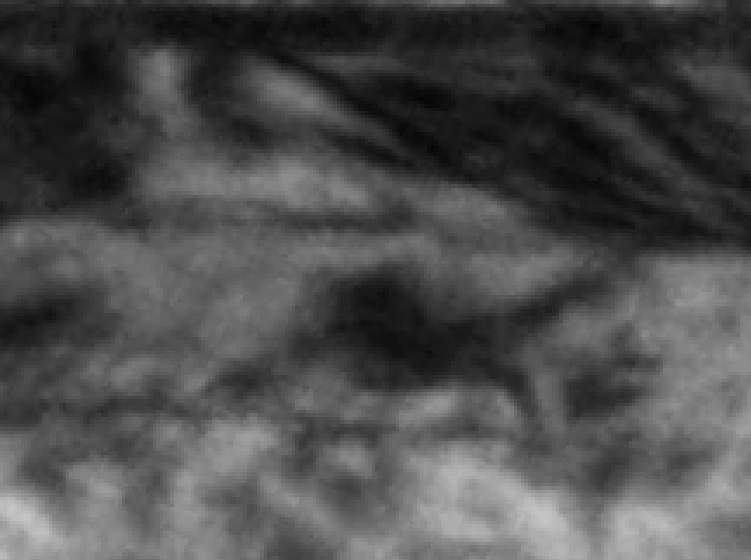
(x)

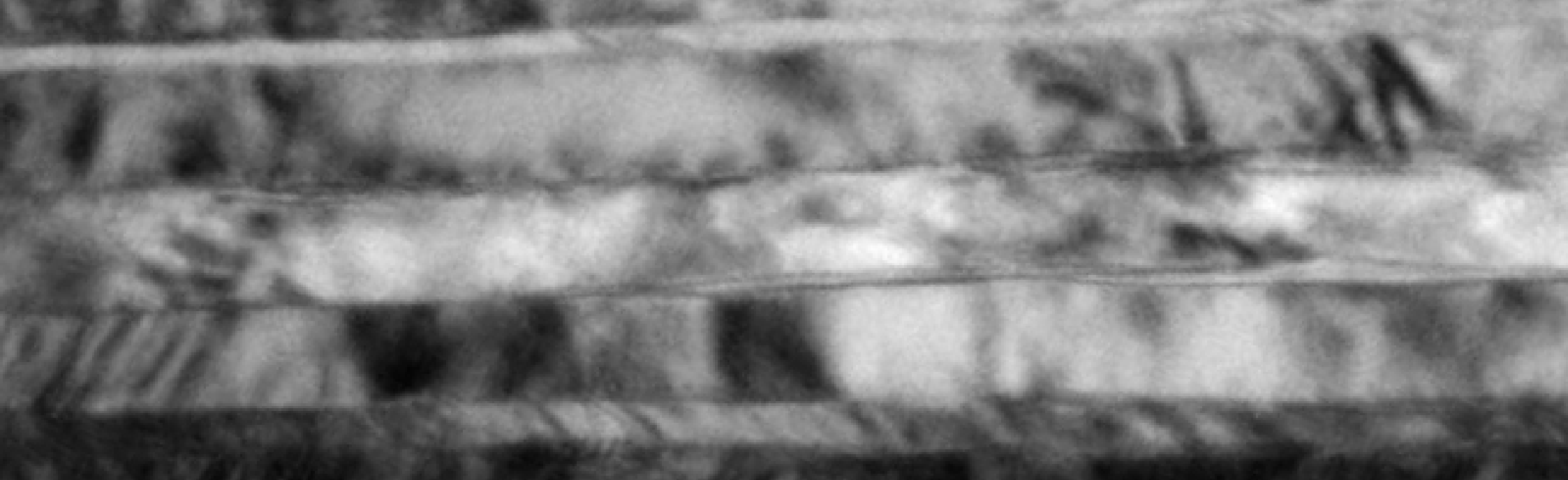

\section{in}

\section{Min}

yenzecos

secan pus

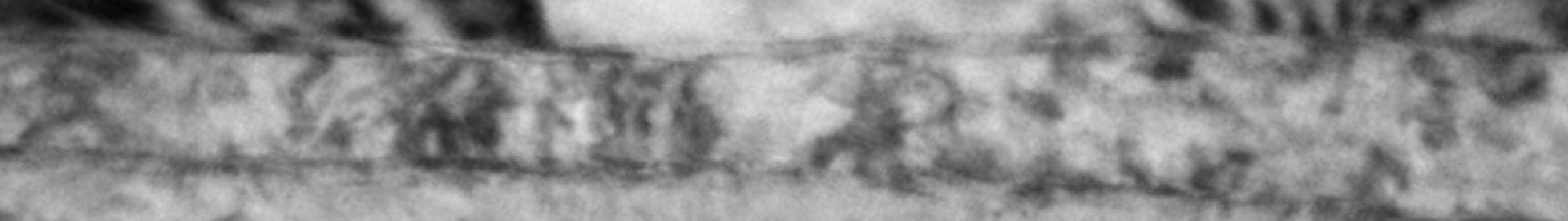
से

\section{b} (10)

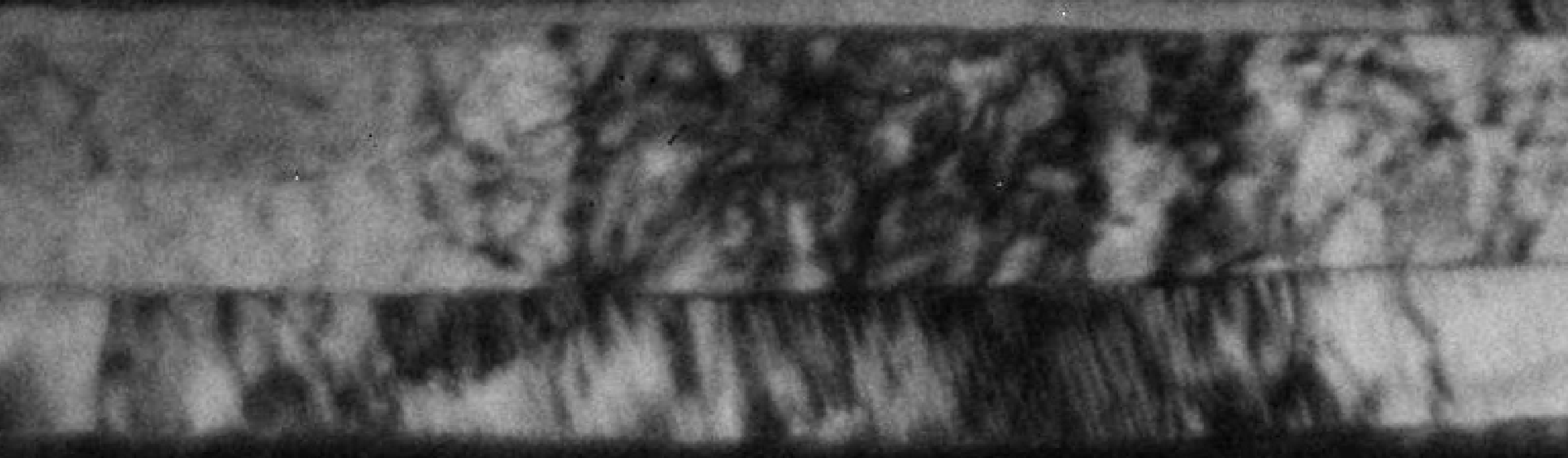
3.

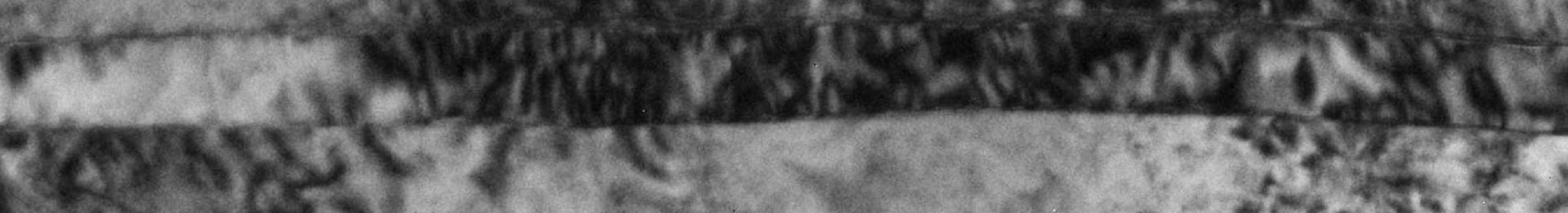
3. 3. 